\title{
HOT DUCTILITY CHARACTERIZATION OF INDUSTRIALLY CAST MICROALLOYED STEELS*
}

Steven George Jansto ${ }^{1}$

\begin{abstract}
The hot ductility behavior of different microalloyed steel chemical compositions was examined simulating the thermal and strain conditions through the straightening or unbending section of the continuous casting machine. All samples were obtained from industrial slab casters ranging from 200 to $300 \mathrm{~mm}$ in slab thickness from steel mills throughout the world including China, Brazil, North America and Europe. The slabs were crack-free and hot rolled into prime quality products. No laboratory heats were tested. Although these microalloyed steels exhibit inherently lower hot ductility behavior, as measured by percent reduction in area at elevated temperature, these steels still exhibit sufficient ductility to satisfactorily meet the unbending stress and strain gradients existing in the straightening section of most casters. The majority of the published hot ductility data, as measured by \% reduction in area (\%RA), were based on laboratory heats and hence, are inaccurate in accessing the propensity for slab cracking on an industrial caster. This situation then results in invalid conclusions for different chemistries. This research has determined the minimum required \%RA for crack-free casting is significantly lower than results based upon previously published laboratory generated data. For example, the literature quotes $40 \%$ RA minimum for $\mathrm{Nb}$-bearing steels when in fact as low as $10 \%$ minimum RA is more than sufficient to assure crack-free casting based upon the extensive testing and analysis performed in this study. Instead of \%RA, the measurement of strain energy has been introduced to evaluate hot ductility behavior. It is concluded that strain energy is a better measure of hot ductility behaviour than \%RA. There is considerable value in the evaluation of the hot stress and strain curves, process metallurgy parameters and their relationship to slab quality instead of just basing hot ductility decisions on simple \%RA measurements.
\end{abstract}

Keywords: Hot ductility; Solidification; Stress strain.

Ph.D., Materials Science and Engineering, Technical and Market Development Manager, CBMM North America, Inc.. Pittsburgh, PA, USA. 


\section{INTRODUCTION}

The level of surface and internal defects impart a direct impact on the overall steel production operating costs, internal and external cost of quality and delivery performance. Niobium (Nb), Titanium (Ti), Vanadium (V) and high Carbon (C) equivalent, high strength microalloyed steel grades are reported as prone to continuous casting surface and crack defects depending upon specific metallurgical factors. [1] There are several published papers based upon the relevance of the traditional ductility trough associated with higher carbon equivalent steels with and without microalloy additions of $\mathrm{Nb}, \mathrm{V}$ and/or $\mathrm{Ti}$. This extensive research has been performed in an attempt to relate the steel chemistry to the hot ductility behavior of low and medium carbon microalloyed steels [2-4]. This early research focus by others has primarily studied the chemistry and optimal composition suggested in order to increase the percent reduction in area during the unbending of the continuous cast slab, thereby raising the ductility trough. These conclusions are based upon laboratry cast heats as well. Although the emphasis on chemistry has been well studied, the steelmaking and process metallurgy parameters of the actual steelmaking operations are rarely correlated to the hot ductility behavior and resultant slab surface quality.

In addition, most hot ductility studies involve laboratory produced heats whereas this research is based solely upon industrial produced samples with an emphasis on process parameters. This research explores different carbon equivalent microalloyed steels which reportedly exhibit inherently lower hot ductility, as measured by percent reduction in area at elevated temperature. Yet, at these low \%RA values, these steels still demonstrate sufficient ductility to satisfactorily meet the unbending stress and strain gradients experienced in actual industrial caster operations and were then successfully hot rolled into prime quality sheets and plates.

\section{MATERIAL AND METHODS}

Hot tensile tests were performed on a Gleeble 3500 thermomechanical system. The industrial steel samples were heated to $1300^{\circ} \mathrm{C}$ at a heating rate of $10^{\circ} \mathrm{C} / \mathrm{sec}$ and held for 5 minutes to assure that the microalloy precipitates went back into solution. The cooling rates are at $60^{\circ} \mathrm{K} /$ minute to the test temperature which simulates the actual casting conditions through the unbending section of the industrial casters that produced the steel samples. Thermocouples on this unit provide signals for accurate feedback control of specimen temperatures. Specimens are clamped securely and tightened by hand in the test chamber of the Gleeble 3500 thermo-mechanical tester. The machined specimens are seated between two water-cooled copper jaws located nearby the specimen threads. Test temperatures were between 700 to $950^{\circ} \mathrm{C}$ to simulate straightening (unbending) temperatures at the industrial casters who provided samples. Strain rates simulated the actual operational strain rate at the caster (i.e. between 0.001 and $0.0001 \mathrm{~mm} / \mathrm{mm} / \mathrm{second}$ ). Figure 1 below schematically presents an example of the heating and cooling schedule for an $800^{\circ} \mathrm{C}$ test temperature example. 
$60^{\circ} \mathrm{K} /$ minute cooling rate to test temperature

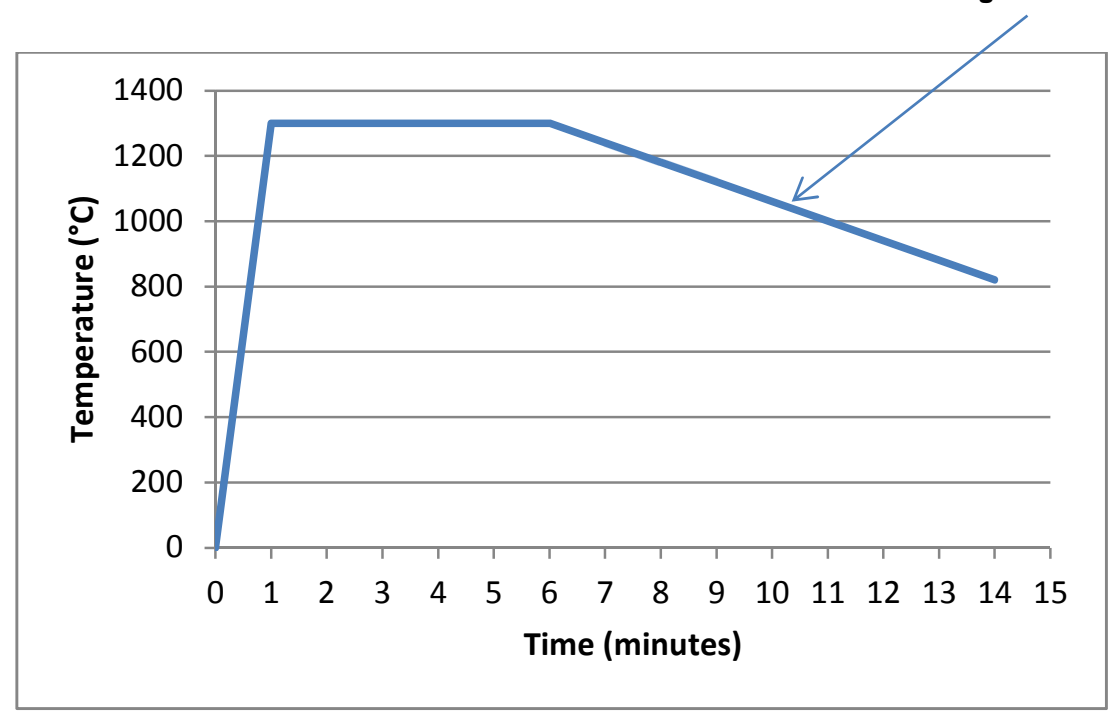

Figure 1. Heating \& cooling schedule example for $800^{\circ} \mathrm{C}$ test.

The strain rates for all of the tests simulated the actual operational strain rate experienced at the unbending section of the casters' who provided samples and process metallurgy data for this global study. The two strain rates employed were between 0.001 and $0.0001 \mathrm{~mm} / \mathrm{mm} / \mathrm{second}$ which is the typical strain rate range globally. The raw data output of force, dynamic gauge measurements, stress and strain were converted into a stress strain curve for each sample. The fracture surface area was measured using a Mitutoyo micrometer and recorded as \%RA of sample fracture surfaces.

\subsection{Sample Location}

In rare cases when other researchers did collect industrial continuous cast slab samples for hot ductility tests, a detailed sketch of the actual sample location and orientation within the slab is often not reported. For example, centerline samples would be affected by segregation versus surface samples or sub-surface samples. In this research, the intent is to determine the hot ductility behavior subsurface at or near the transition in grain size from the equiaxed chill zone to the columnar grain zone. This zone represents a variable grain size due to the transition from equiaxed to columnar grains and a high residual strain region exists due to the mixed grain microstructure. Samples were extracted from the cast slabs at the $20 \mathrm{~mm}$ to the $80 \mathrm{~mm}$ depth below the surface. The objective is to capture the Equiaxed-ColumnarGrain (EACLG) transition zone [5] which has higher internal residual strain due to the mixed grain feature of this subsurface region. Samples were saw-cut from the full size master slab to minimize any distortion that may result from the torch cutting which would also change the cast slab microstructure and grain size. Figure 2 illustrates this unique subsurface sample location for the hot ductility tensile tests performed in this study. 


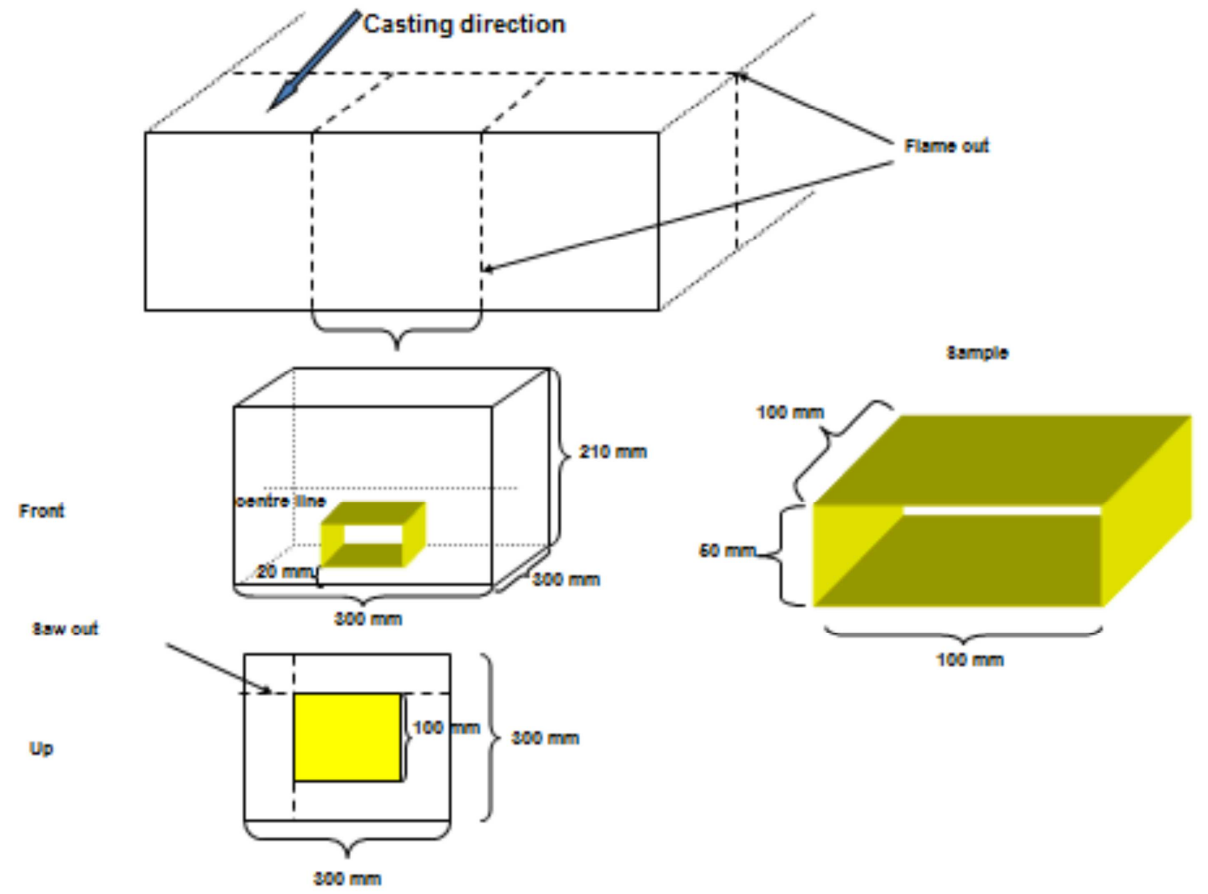

Figure 2. Continuous cast slab sample location and orientation.

\subsection{Chemical Compositions}

A variety of slab samples were obtained from industrial continuous casters. The microalloy compositions tested are shown in Table 1 and range from $0.045 \%$ to $0.253 \% \mathrm{C}$ at various $\mathrm{Nb}, \mathrm{V}$, and/or Ti compositions.

Table 1. Industrial sample compositions

\begin{tabular}{ccccccccccccccc}
\hline ID & $\mathbf{C}$ & $\mathbf{M n}$ & $\mathrm{Si}$ & $\mathrm{Nb}$ & $\mathbf{V}$ & $\mathrm{Ti}$ & $\mathrm{Mo}$ & $\mathrm{Cr}$ & $\mathrm{Cu}$ & $\mathrm{Ni}$ & $\mathrm{Al}$ & $\mathbf{S}$ & $\mathbf{P}$ & $\mathbf{N}$ \\
\hline 1A & .158 & 1.45 & .454 & .041 & .009 & .004 & .004 & .048 & .019 & .046 & .033 & .002 & .013 & .0058 \\
\hline 2A & .154 & 1.45 & .455 & .042 & .009 & .005 & .006 & .053 & .027 & .050 & .033 & .001 & .014 & .0027 \\
\hline 3B & .074 & 1.55 & .209 & .050 & .073 & .019 & .005 & .046 & .035 & .049 & .035 & .002 & .009 & .0040 \\
\hline 4C & .132 & 1.57 & .260 & .036 & .079 & .031 & .005 & .046 & .015 & .041 & .035 & .002 & .008 & .0058 \\
\hline 5D & .411 & 1.68 & .210 & .002 & .090 & .017 & .004 & .053 & .024 & .046 & .033 & .007 & .013 & .0061 \\
\hline 6E & .141 & 1.39 & .390 & .040 & .078 & .009 & .006 & .047 & .026 & .045 & .029 & .004 & .011 & .0062 \\
\hline 7F & .142 & 0.61 & .640 & .002 & .007 & .005 & .497 & 1.41 & .016 & .059 & .039 & .001 & .008 & .0083 \\
\hline 8G & .253 & 1.05 & .503 & .002 & .008 & .028 & .184 & .387 & .016 & .369 & .044 & .002 & .009 & .0052 \\
\hline 9H & .072 & 1.49 & .250 & .036 & .008 & .015 & .004 & .044 & .142 & .382 & .036 & .002 & .009 & .0056 \\
\hline 10I & .081 & 0.99 & .205 & .002 & .010 & .028 & .006 & 1.05 & .022 & .063 & .036 & .004 & .010 & .0047 \\
\hline 11J & .072 & 1.41 & .189 & .023 & .010 & .014 & .007 & .053 & .023 & .051 & .035 & .005 & .011 & .0051 \\
\hline 12K & .147 & 1.40 & .377 & .010 & .009 & .005 & .007 & .067 & .033 & .072 & .039 & .002 & .011 & .0041 \\
\hline 13L & .045 & 1.90 & .179 & .084 & .013 & .098 & .006 & .042 & .045 & .051 & .026 & .002 & .008 & .0063 \\
\hline
\end{tabular}




\section{RESULTS AND DISCUSSION}

A key objective of this research is to determine the \%RA for industrial cast slabs which exhibit no cracks or surface quality issues. This data is presented to establish a baseline for the industry. Process metallurgy data was recorded as well, but is outside the scope for presentation within this paper. The \%RA at temperature data for crack-free low carbon, peritectic and medium carbon produced steel slab compositions is compiled below in Table 2 .

Table 2. Percent reduction in area at temperature

\begin{tabular}{|c|c|c|c|c|c|c|}
\hline Sample & $700^{\circ} \mathrm{C}$ & $800^{\circ} \mathrm{C}$ & $850^{\circ} \mathrm{C}$ & $900^{\circ} \mathrm{C}$ & $950^{\circ} \mathrm{C}$ & $\begin{array}{c}\text { Strain } \\
\text { Rate }\end{array}$ \\
\hline \multirow[t]{2}{*}{$1 \mathrm{~A}$} & 58.2 & 27.6 & 30.6 & 43.1 & NA & 0.001 \\
\hline & 44.6 & 14.5 & 16.6 & 23.2 & NA & 0.0001 \\
\hline \multirow[t]{2}{*}{$2 A$} & 64.5 & 43.3 & 54.0 & 23.2 & NA & 0.001 \\
\hline & 49.5 & 21.5 & 29.9 & 42.5 & NA & 0.0001 \\
\hline \multirow[t]{2}{*}{$3 B$} & 66.3 & 48.9 & 67.2 & 68.8 & NA & 0.001 \\
\hline & NA & 33.9 & 54.7 & 72.1 & NA & 0.0001 \\
\hline \multirow[t]{2}{*}{$4 C$} & 73.0 & NA & 68.1 & 86.0 & 89.0 & 0.001 \\
\hline & 64.1 & NA & 58.0 & 81.1 & 85.0 & 0.0001 \\
\hline \multirow[t]{2}{*}{$5 \mathrm{D}$} & 50.3 & 70.7 & NA & 91.7 & 90.9 & 0.001 \\
\hline & 31.8 & 41.5 & NA & 82.9 & 85.9 & 0.0001 \\
\hline \multirow[t]{2}{*}{$6 \mathrm{E}$} & 61.4 & 38.0 & 53.8 & 57.4 & NA & 0.001 \\
\hline & 43.9 & 20.1 & 27.4 & 36.2 & NA & 0.0001 \\
\hline \multirow[t]{2}{*}{$7 F$} & 86.6 & 46.9 & 65.9 & 57.5 & NA & 0.001 \\
\hline & 74.2 & 38.5 & 45.0 & 37.1 & NA & 0.0001 \\
\hline \multirow[t]{2}{*}{$8 \mathrm{G}$} & 73.2 & 85.2 & 93.2 & 91.3 & NA & 0.001 \\
\hline & NA & NA & NA & NA & NA & 0.0001 \\
\hline \multirow[t]{2}{*}{$9 \mathrm{H}$} & 72.2 & 47.9 & NA & 75.7 & 86.7 & 0.001 \\
\hline & 54.1 & 24.1 & NA & 55.1 & NA & 0.0001 \\
\hline \multirow[t]{2}{*}{101} & 75.8 & 73.5 & NA & 94.2 & 95.6 & 0.001 \\
\hline & 74.6 & 61.4 & NA & 92.5 & 93.9 & 0.0001 \\
\hline \multirow[t]{2}{*}{$11 \mathrm{~J}$} & 58.7 & 59.2 & NA & 78.0 & 81.0 & 0.001 \\
\hline & 75.6 & 45.1 & NA & 66.0 & 77.6 & 0.0001 \\
\hline \multirow[t]{2}{*}{$12 \mathrm{~K}$} & 73.7 & 39.4 & 53.3 & 68.4 & NA & 0.001 \\
\hline & 57.2 & 24.1 & 25.6 & 31.2 & NA & 0.0001 \\
\hline \multirow[t]{2}{*}{$13 \mathrm{~L}$} & 31.6 & 15.9 & 31.6 & 44.0 & NA & 0.001 \\
\hline & 33.3 & 11.4 & 26.7 & 30.0 & NA & 0.001 \\
\hline
\end{tabular}

All industrially cast samples, Strain rate in $\mathrm{mm} / \mathrm{mm} / \mathrm{sec}$

\subsection{Compositional Effect on Hot Ductility Behavior}

Previously published literature over the past 25 years placed significant focus upon the effects of various compositional elements on the \%RA performance. Conclusions were made indicating various elemental preferences and compositional combinations to improve hot ductility behavior and perceived reduced incidence of transverse cracking or other surface quality issues. Often the carbon level was not emphasized in these analyses, but the microalloys of $\mathrm{Nb}, \mathrm{V}$ and $\mathrm{Ti}$ were emphasized. The lack of process metallurgy data and industrial samples often resulted in physical metallurgy mechanisms and recommended elemental preferences that are disconnected from the actual process metallurgy in an industrial setting. Nevertheless, the laborious laboratory task of trying to simulate an industrial caster was attempted, but in the end 
very difficult to nearly impossible to emulate industrial practices. In fact, some of the laboratory generated conclusions as recent as 2010 [6], especially involving the compositional effects on hot ductility behavior, incorrectly over emphasize the role of elements without respectable regard for the actual operational parameters such as superheat, casting speed, mould level fluctuations, primary and secondary cooling and fundamental solidification considerations.

A typical microalloy comparison of hot ductility performance is shown below in Figure 3 from the literature for lab heats. [7] The typical hot ductility trough is illustrated especially between $800-850^{\circ} \mathrm{C}$.

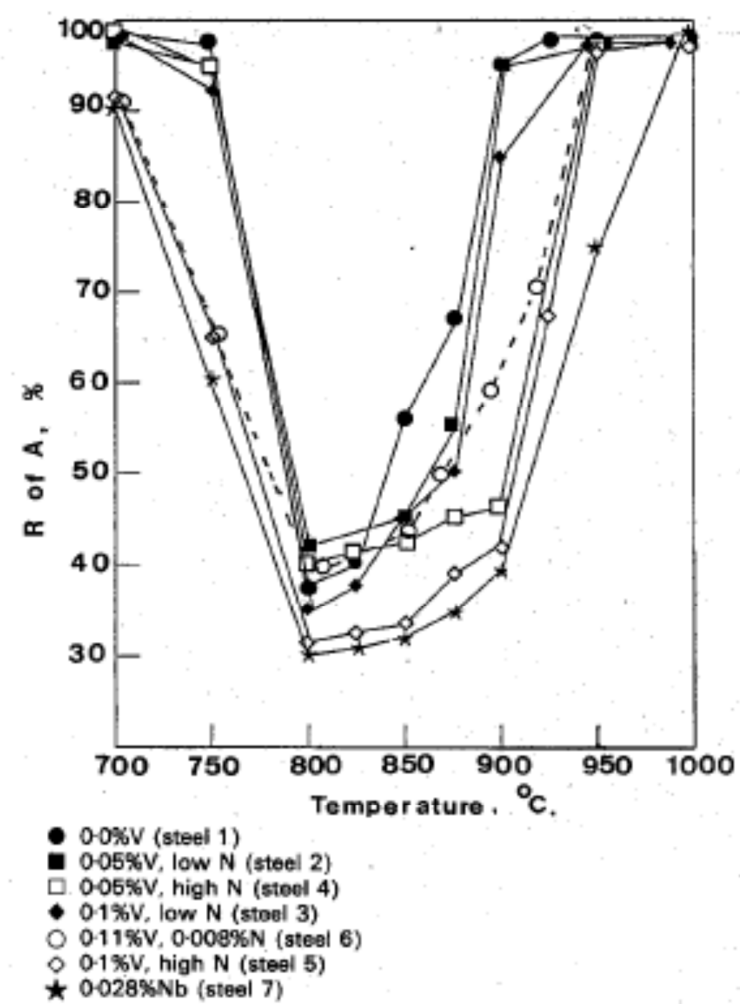

Figure 3. Hot ductility curves for a series of steels with different levels of $\mathrm{V}$ and $\mathrm{N}$ and $\mathrm{Nb}$. [7]

It is inferred that deeper and wider troughs caused by certain compostions will result in cracking through the straigthening section of an industrial caster. As described in the literature review references $[1,2,6]$, most of the literature has pointed toward the direct positive and/or negative influence of $\mathrm{Nb}, \mathrm{Ti}$ and/or $\mathrm{V}$ on hot ductility behavior. However, this analysis has been a bit distorted over the years and implications that a deeper and wider ductility trough introduces transverse cracks. It is totally self-limited when conclusions in the literature recommend the elimination of a given microalloy from a material design to improve perceived castability and surface quality and sacrificing enhanced mechanical properties in the downstream hot rolled product due to the elimination of a given microalloy.

\subsection{Percent Reduction in Area Results}

An example of the Gleeble test for \%RA of an industrial sample is illustrated in Figure 4. 


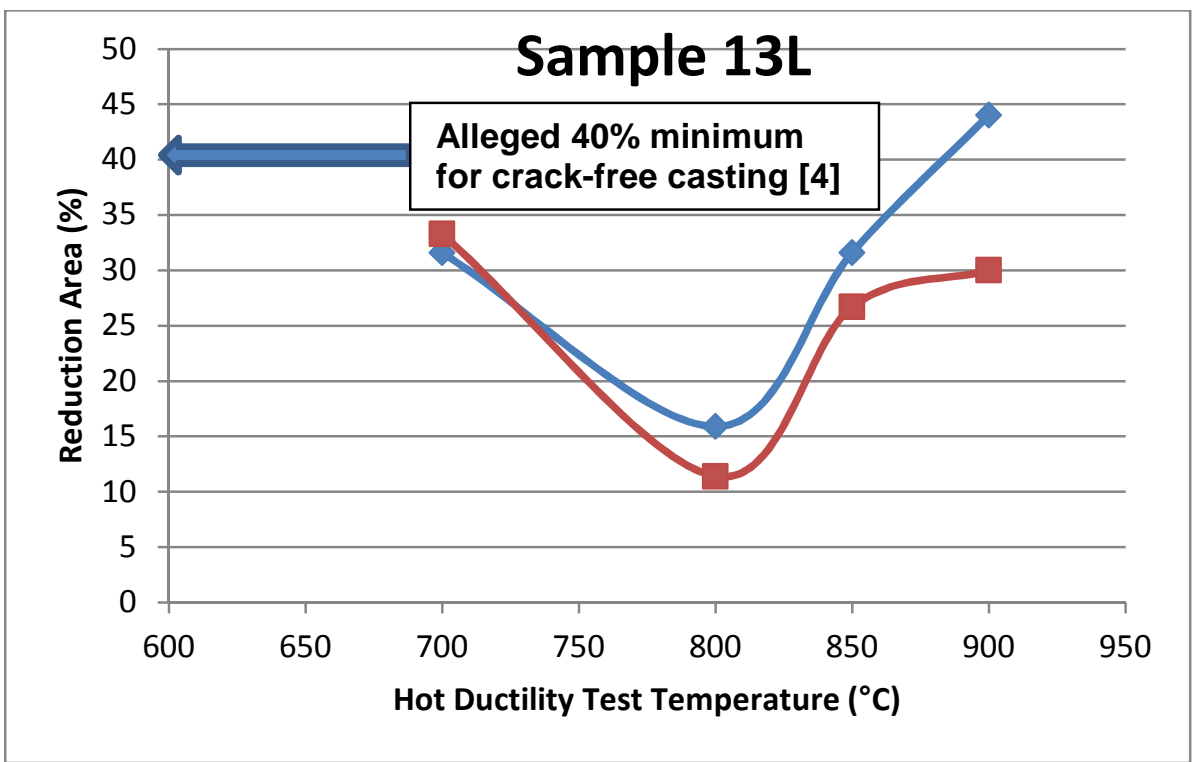

$.045 \% \mathrm{C}$
$1.90 \% \mathrm{Mn}$
$.179 \% \mathrm{Si}$
$.084 \% \mathrm{Nb}$
$.013 \% \mathrm{~V}$
$.098 \% \mathrm{Ti}$
$.006 \% \mathrm{Mo}$
$.042 \% \mathrm{Cr}$
$.045 \% \mathrm{Cu}$
$.051 \% \mathrm{Ni}$
$.0003 \% \mathrm{~B}$
$.026 \% \mathrm{Al}$
$.002 \% \mathrm{~S}$
$.008 \% \mathrm{P}$
$.0026 \% \mathrm{Ca}$
$.0063 \% \mathrm{~N}$

Strain rate (blue curve ) $=0.001$ (red curve) $=0.0001$

Figure 4. \% Reduction in area versus test temperature.

Each microalloy has a purpose to serve. With proper melting and casting parameters, these microalloy compositions are well within the capability of producing crack-free slabs regardless of the individual microalloy, the combination of microalloys and the carbon equivalent of the grade even at as low as 10\%RA, yet published literature quoted $40 \%$ minimum \%RA [4] to assure crack-free casting of Nb bearing heats. Due to this lack of correlation between \%RA from laboratory generated heat samples and actual performance in an industrial slab or bloom caster, it was decided to compare strain energy as a better measure for prediction of the hot ductility behavior.

\subsection{Strain Energy Calculations}

The strain rates for all of the tests simulated the actual operational strain rate at the unbending section of the casters' providing the samples for this study. The two strain rates employed were between 0.001 and $0.0001 \mathrm{~mm} / \mathrm{mm} / \mathrm{second}$. The raw data output of force, dynamic gauge, measurements, stress and strain were converted into a stress strain curve for each sample. (See Figure 5 as an example.) 


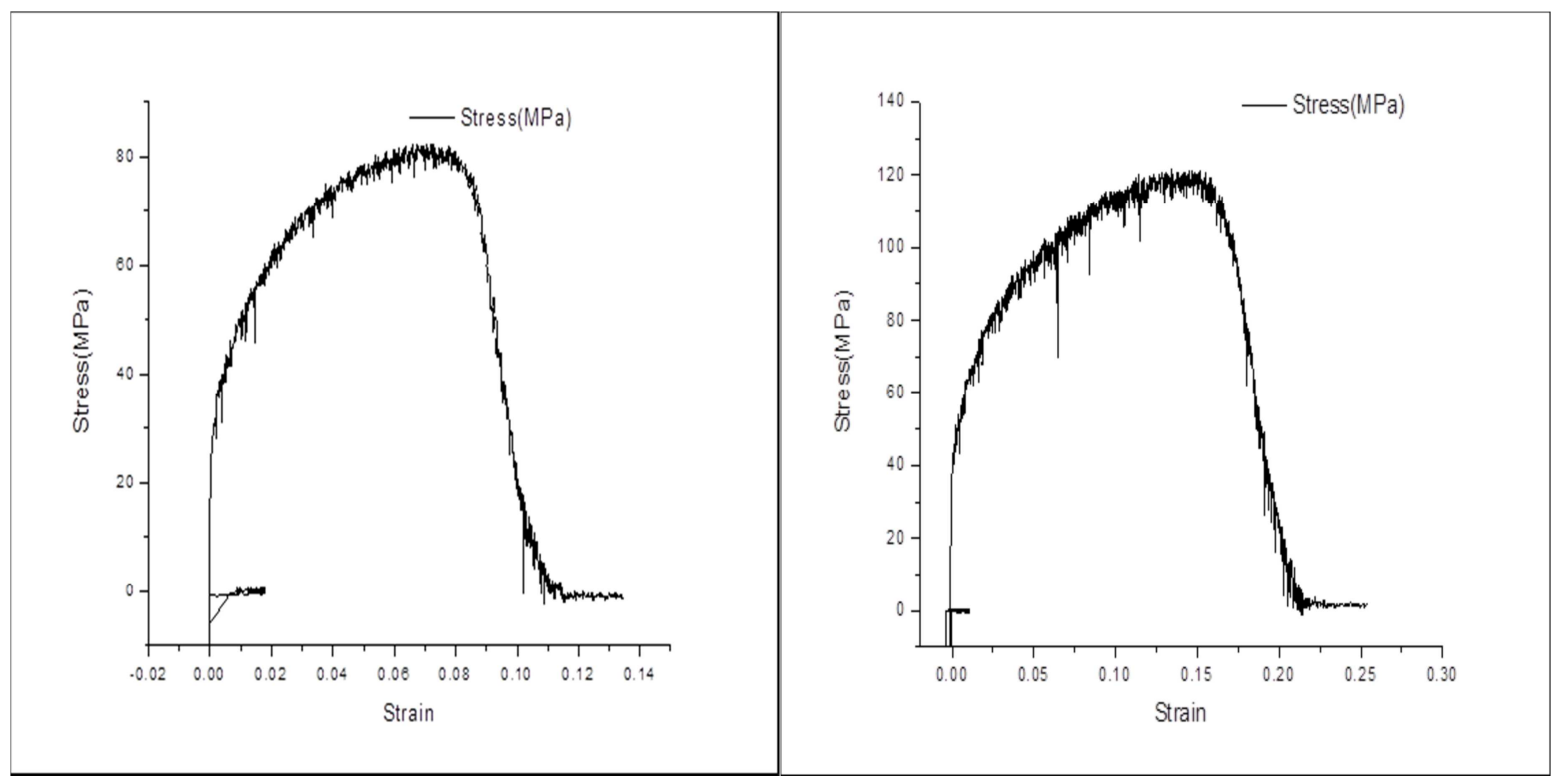

Figure 5. Stress strain curve (sample $1 \mathrm{~A}$ at $800^{\circ} \mathrm{C}$ and 0.0001 (left) \& 0.001 strain rate (right)

Note that at the higher strain rate for Sample $1 \mathrm{~A}(0.158 \% \mathrm{C}-0.041 \% \mathrm{Nb})$, the ultimate tensile strength is $120 \mathrm{MPa}$ versus $80 \mathrm{MPa}$ at the lower strain rate and 0.155 strain versus 0.068 strain respectively. The strain at fracture for the 0.001 strain rate is 0.254 versus 0.135 for the lower strain rate. The area under the $\sigma-\varepsilon$ curve up to a given value of strain is defined as the total mechanical energy per unit volume $\left(U^{*}\right)$ consumed by a material in the process of straining to that given value. This equation (Equation 1) is shown by:

$$
U^{*}=(1 / V) \int P d L=\int_{0}^{L}\left(P / A_{0}\right)\left(d L / L_{0}\right)=\int_{0}^{\varepsilon} \sigma d \varepsilon
$$

In the absence of slip and other mechanisms for energy dissipation, this mechanical energy is stored reversibly within the material as strain energy. The strain energy increases quadratically with the stress or strain (i.e. as the strain increases then the energy stored by a given increment of additional strain grows as the square of the strain). The area up to the yield point is termed the modulus of resilience. The total area up to fracture is termed the modulus of toughness. The strain energy is then calculated by integration of the area under the stress-strain curve. Table 3 compares the strain energy to the \%RA data based upon the stress strain curve in Figure 5.

Table 3. Strain energy and \% reduction in area comparison table

\begin{tabular}{ccc}
\hline Strain Rate & LOW & HIGH \\
\hline $\begin{array}{c}\text { Strain Rate } \\
(1 / \mathrm{sec})\end{array}$ & 0.0001 & 0.001 \\
\hline $\begin{array}{c}\text { Strain Energy } \\
(\mathrm{Mpa}-\end{array}$ & 6.663 & 19.380 \\
$\mathrm{~mm} / \mathrm{mm})$ & & \\
\hline $\begin{array}{c}\text { \%Reduction } \\
\text { in Area }\end{array}$ & 14.5 & 27.6 \\
\hline
\end{tabular}

The strain energy results were then calculated for each sample by integration of the area under the stress strain curve (MPA-mm/mm). Presentation of the strain energy results and comparison to the \%RA data at $800^{\circ} \mathrm{C}$ are summarized in Table 4. 
Table 4. Strain energy and percent reduction in area results

\begin{tabular}{|c|c|c|c|c|c|c|c|}
\hline Sample* & $\begin{array}{l}\text { Casting } \\
\text { Speed } \\
(\mathrm{m} / \mathrm{min})\end{array}$ & $\begin{array}{l}\text { SE at } \\
800^{\circ} \mathrm{C} \\
0.001\end{array}$ & $\begin{array}{l}\text { SE at } \\
800^{\circ} \mathrm{C} \\
0.0001\end{array}$ & $\Delta_{\mathrm{SE}}$ & $\begin{array}{l}\% \mathrm{RA} \\
\text { at } \\
\mathbf{8 0 0}^{\circ} \mathrm{C} \\
0.001\end{array}$ & $\begin{array}{l}\text { \% RA } \\
\text { at } \\
800{ }^{\circ} \mathrm{C} \\
0.0001\end{array}$ & $\Delta_{\mathrm{RA}}$ \\
\hline$\overline{1 A}$ & 1.16 & 19.381 & 6.663 & 12.718 & 27.6 & 14.5 & 13.1 \\
\hline $2 \mathrm{~A}$ & 1.16 & & 11.466 & & 43.3 & 21.4 & 21.9 \\
\hline 3B & 1.22 & 41.269 & 22.931 & 18.338 & 48.9 & 33.9 & 15.0 \\
\hline $4 C$ & 1.16 & 58.142 & 44.564 & 13.688 & 68.1 & 58.0 & 10.1 \\
\hline 5D & 1.35 & 46.489 & & & 70.7 & & \\
\hline $6 E$ & 1.16 & 27.291 & 8.375 & 18.916 & 38.0 & 20.1 & 17.9 \\
\hline $7 F$ & 1.17 & 21.927 & 12.742 & 9.185 & 46.9 & 38.5 & 8.4 \\
\hline $8 G$ & 1.16 & 37.986 & & & 85.2 & & \\
\hline $9 \mathrm{H}$ & 0.89 & 38.886 & & & 47.9 & & \\
\hline 10I & 1.35 & 52.427 & 24.554 & 27.873 & 73.5 & 61.4 & 12.1 \\
\hline 11J & 1.09 & 40.695 & 18.760 & 21.935 & 59.2 & 45.1 & 14.1 \\
\hline $12 K$ & 1.16 & 23.372 & 8.404 & 14.968 & 39.4 & 24.1 & 15.3 \\
\hline 13L & 1.18 & 12.270 & 4.094 & 8.176 & 15.0 & 11.4 & 3.6 \\
\hline
\end{tabular}

This strain energy approach has not been considered in the field of hot ductility behavior of continuous cast steels through the unbending section of the casting. Thus, this research introduces the strain energy relation to hot ductility behavior and the related significant processing variables.

\subsection{Stress Strain Curve Correlation Analysis}

A strong $R^{2}$ of 0.906 was determined between the strain energy and the ultimate tensile strength (UTS) and 0.919 for the strain at UTS as shown in Figure 6 and 7.

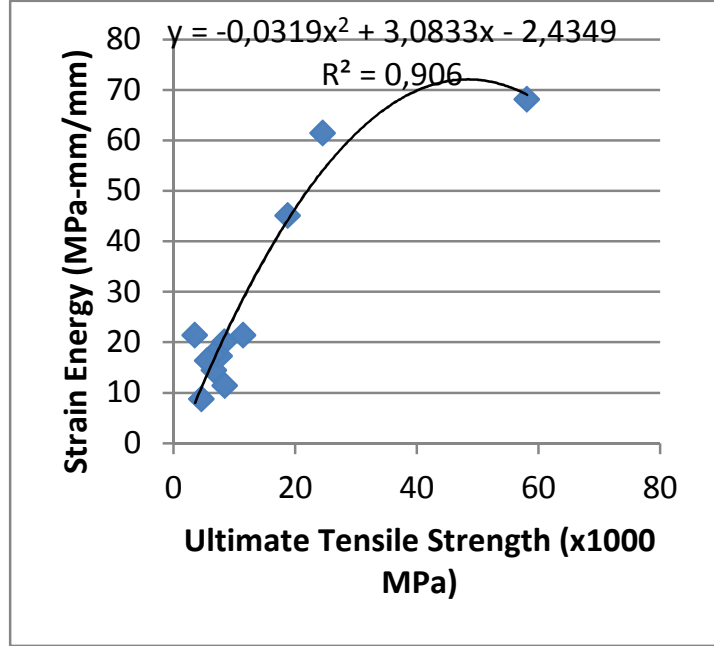

Figure 6. Strain energy versus UTS at $800^{\circ} \mathrm{C}$.

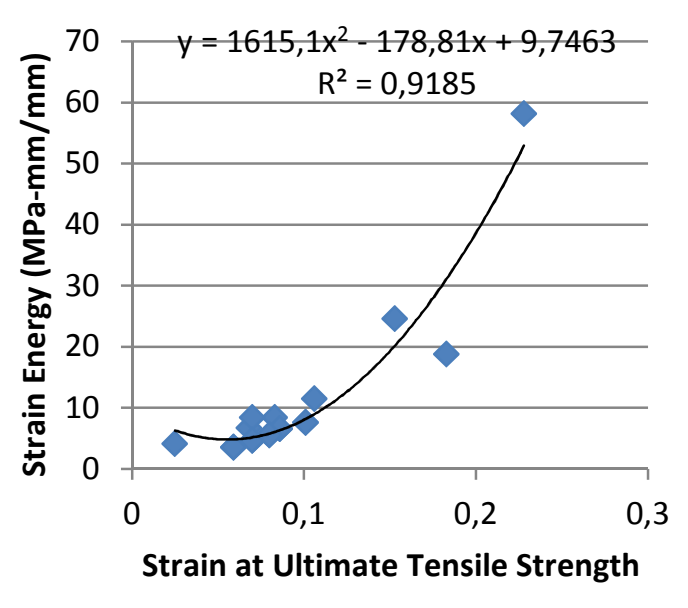

Figure 7. Strain energy versus strainuts at $800^{\circ} \mathrm{C}$.

A comprehensive analysis of the stress strain curve data and correlation analysis was performed between the strain energy and yield strength, UTS as well as the strain at UTS for the temperature exhibiting the lowest strain energy. Comparatively, the $R^{2}$ for \%RA versus UTS is 0.728 and strain at UTS is only 0.137 . The key factor affecting the subsurface crack propagation at the EACLZ will be the tolerable strain at the UTS. Additional investigation is suggested for future research work to further study the strain energy relationship and hot ductility behavior. 


\section{CONCLUSION}

The conclusion indicates that a low \%RA does not necessarily equate to the incidence of transverse cracking under proper processing conditions. The actual relevance of the \%RA criterion for any chemistry steel should be met with skepticism when designing microalloy grades. The hot ductility behavior was studied in relation to the chemical composition, process metallurgy variables and hot ductility behavior for a variety of microalloyed and non-microalloyed steel chemistries. All samples were obtained from industrial operations. Percent RA has been the traditional assessment tool to characterize the hot ductility behaviors and potential propensity for cracking. This study introduces the strain energy as a better measure for assessing hot ductility behavior and exhibits a stronger correlation coefficient to strain at ultimate tensile strength (UTS) than \%RA.The application of laboratorygenerated heat data does not accurately emulate the hot ductility behavior of samples obtained from industrial casters. This research determined that the minimum required \%RA for crack-free casting is inaccurate and significantly overstates the $\%$ RA required for crack-free castability. The literature quotes $40 \%$ RA minimum for $\mathrm{Nb}$-bearing steels when in fact, as low as $10 \%$ minimum $\mathrm{RA}$ is more than sufficient to assure crack-free casting based upon the extensive testing, operational parameter review and analysis performed in this study according to actual operational results and data. In conclusion, strain energy is a better measure of hot ductility behavior than \%RA. There is considerable value in the evaluation of the hot stress and strain curves, process metallurgy parameters and their relationship to slab quality.

\section{REFERENCES}

1 B. Mintz, S. Yue and J.J. Jonas. Hot Ductility of Steels and Its Relationship to the Problem of Transverse Cracking During Continuous Casting. International Materials Review. 1991; Vol. 36, No. 5:189.

2 B. Mintz. The Influence of Composition on the Hot Ductility of Steels and to the Problem of Transverse Cracking. ISIJ International. 1999; Vol. 39, No. 9: 833 - 855.

3 Y. Maehara, K. Yasumoto, H. Tomono, T. Nagamichi and Y. Ohmori, Y. Surface Cracking Mechanism of Continuously Cast Low Carbon Low Alloy Steel Slabs.

Materials Science \& Technology. 1990; Vol. 6: 793-805.

4 B. Mintz. Importance of $\mathrm{Ar}_{3}$ Temperature in Controlling Ductility and Width of Hot Ductility Trough in Steels and its Relationship to Transverse Cracking. Materials Science Technology. 1996; Vol. 12: 132 - 138.

5 S. Jansto. Hot Ductility Characterization of Laboratory versus Industrially Produced Continuously Cast Microalloyed Steels. Materials Science \&Technology. 2013; 925-932. B. Mintz and D.N. Crowther. Hot Ductility of Steels and Its Relationship to the Problem of Transverse Cracking in Continuous Casting. International Materials Reviews. 2010; Vol. 55, No. 2: 168-196.

7 B. Mintz and R. Abushosha, R. Influence of Vanadium on Hot Ductility of Steel. Ironmaking and Steelmaking. 1993; Vol. 20: 445 - 452. 